\title{
Quality Versus Quantity Debate in Swimming: Perceptions and Training Practices of Expert Swimming Coaches
}

\author{
by \\ Frank J. Nugent ${ }^{1}$, Thomas M. Comyns ${ }^{1}$, Giles D. Warrington ${ }^{1}$
}

\begin{abstract}
The debate over low-volume, high-intensity training versus high-volume, low-intensity training, commonly known as Quality versus Quantity, respectively, is a frequent topic of discussion among swimming coaches and academics. The aim of this study was to explore expert coaches' perceptions of quality and quantity coaching philosophies in competitive swimming and to investigate their current training practices. A purposeful sample of 11 expert swimming coaches was recruited for this study. The study was a mixed methods design and involved each coach participating in 1 semi-structured interview and completing 1 closed-ended questionnaire. The main findings of this study were that coaches felt quality training programmes would lead to short term results for youth swimmers, but were in many cases more appropriate for senior swimmers. The coaches suggested that quantity training programmes built an aerobic base for youth swimmers, promoted technical development through a focus on slower swimming and helped to enhance recovery from training or competition. However, the coaches continuously suggested that quantity training programmes must be performed with good technique and they felt this was a misunderstood element. This study was a critical step towards gaining a richer and broader understanding on the debate over Quality versus Quantity training from an expert swimming coaches' perspective which was not currently available in the research literature.
\end{abstract}

Key words: high-intensity training, high-volume training, long term athlete development, coaching philosophy, mixed methods.

\section{Introduction}

Swimming is one of the largest Olympic sports with 32 pool events ranging in distance from 50 to $1500 \mathrm{~m}$. The Gold Medal winning times at the Rio 2016 Olympics ranged in duration from $21.4 \mathrm{~s}$ for the $50 \mathrm{~m}$ event to $14 \mathrm{~min} 34.57 \mathrm{~s}$ for the $1500 \mathrm{~m}$ event. Twenty six out of thirty two (81\%) Olympic level swimming events are competed over a race distance of $200 \mathrm{~m}$ or less, for typical duration of less than $2 \min 20 \mathrm{~s}$. Despite the relatively short distance and duration of the majority of events, swimming coaches are widely acknowledged to place a strong emphasis on high-volume, low-intensity training (HVT) (Lang and Light, 2010).

The relevance of HVT to the physiological requirements of many swimming events is a long standing topic of discussion in the scientific literature (Aspenes and Karlsen, 2012). One of the earliest researchers on the topic, David Costill, summarised this by stating "it is difficult to understand how swimming at speeds that are markedly slower than the competitive pace for 3 to 4 hours per day will prepare the swimmer for the supramaximal efforts of competition" (Costill et al., 1991). In the swimming community, this has been referred to as the debate over "Quality vs Quantity" (Maglischo, 2003; Salo and Riewald, 2008). On the quality side of the debate, there is the suggestion that swimmers can reduce training mileage with no loss of endurance capacity if they

1 - Department of Physical Education and Sport Sciences, University of Limerick, Limerick, Ireland. 
perform their swimming intervals at faster speeds, whereas the quantity or HVT side suggests that more swimming mileage will produce greater endurance capacity and thus faster swimming times.

A recently published systematic review by Nugent et al. (2016) investigated the effects of low-volume, high-intensity training (HIT), otherwise known as quality training, on performance in competitive swimmers from youth to masters level. HIT is defined as repeated bouts of high intensity exercise from maximal lactate steady state to supramaximal exercise intensity, interspersed with recovery periods of low intensities or complete rest (Hawley et al., 1997). Seven studies met the inclusion criteria for the review. The studies ranged in duration from 4 weeks to 4 years. Six out of the 7 studies found that a HIT intervention resulted in significant improvements in outcome measures of physiological performance. Four of the 7 studies found that HIT led to significant improvements in swimming performance, whilst none of the 7 studies observed a reduction in physiological or swimming performance. Despite some of the positive findings reported by HIT studies in swimming, the applications of these findings to the long term development of a youth swimmer may be limited as a number of the current studies are short in duration (only 4 to 6 weeks). In addition, youth swimming performance has been found not to be entirely determined by physiological variables, but more multifactorial in nature involving complex interplay of kinematics, efficiency and hydrodynamics (Morais et al., 2016; Morais et al., 2015). Therefore future HIT interventions should aim to account for some of these variables.

In the swimming community, the recent success of competitive swimmers who train using a derivative of HIT called Ultra-Short Race-Pace Training (USRPT) has further fuelled this debate (Beliaev, 2015; Goldsmith, 2016; Stott, 2014). USRPT is defined as high intensity swimming in sets that match the best achieved velocities of individuals' races and consists of a high number of repetitions over short distances with brief rests, generally no longer than 20 seconds (Rushall, 2011). Competitive swimmers who advocate USRPT have been reported to average around 9 $11 \mathrm{~km}$ per week (Stott, 2014). This is in stark contrast to the more traditional $38-44 \mathrm{~km}$ per week for youth swimmers reported by Hibberd and Myers (2013) and the $54 \pm 19 \mathrm{~km}$ per week reported for elite swimmers (Pyne et al., 2001). Concerns over long term athlete development (LTAD) models that advocate HVT for youth swimmers have been previously expressed by English swimming coaches (Lang and Light, 2010). The main concern expressed by the swimming coaches was that the LTAD model had an overemphasis on training volume leading to the neglect of technique. A subsequent commentary article by Greyson et al. (2010) suggested that developing the aerobic energy system in swimmers, primarily through the use of HVT, was crucial in order to target the optimal window of opportunity for aerobic development as proposed in the LTAD model (Balyi and Hamilton, 2004). However, the windows of opportunity within the LTAD model are largely theoretical and lack supporting longitudinal research (Lloyd and Oliver, 2012). Despite this, anecdotal evidence suggests that many of the top swimming nations in the world advocate HVT for youth swimmers and their success at Olympic level is evident.

The emerging evidence in the literature and within the swimming community on the debate over HIT vs HVT, commonly known as Quality vs Quantity, provides a strong rationale to conduct this study. The experiential knowledge of expert coaches has been suggested to play a useful role in enhancing the understanding of sports performance (Greenwood et al., 2012). This experiential knowledge is often based on day to day practice and performance experiences throughout a coaches' career and may provide rich information on a topic (Greenwood et al., 2012). Therefore the aim of this study was to explore expert swimming coaches' experiential knowledge of the impact of quality and quantity coaching philosophies on swimming performance and to investigate their current training practices.

\section{Material and Methods}

\section{Participants}

The participants in this study were 11 expert swimming coaches: gender (10 males, 1 female), age ranged from 35 to 60 years ( $47.6 \pm 7$ years), swim coaching experience ranged from 16 to 40 years ( $27 \pm 8$ years), education (9 coaches 
were educated to the $3^{\text {rd }}$ level, 2 coaches were educated to the $2^{\text {nd }}$ level) and employment (5 parttime swim coaches, 6 full-time swim coaches). In addition, the coaches were personally responsible for coaching swimmers to the following major international events: 3 coaches had coached multiple swimmers to the Olympic Games, 1 to the Paralympic Games, 4 to the World Senior Championships, 2 to the European Senior Championships and 1 to the World Junior Championships.

\section{Measures}

The study was a mixed methods design and involved the coaches partaking in 1 semistructured interview and completing 1 closedended questionnaire. A mixed methods design was appropriate to address the research aim as the combination of qualitative and quantitative data may allow for a better understanding of a phenomenon and enhances the overall strength of a research study (Creswell, 2013).

A semi-structured interview was used to provide the basis for an exploration of the participants' experiences, opinions and to elicit truly open ended responses (Patton, 2015). The interviews ranged in duration from 22 to 55 minutes $(M=39$ minutes). An interview topic guide was designed specifically for this study and was pilot tested on two expert swimming coaches. As suggested by Mayan (2009), the interview topic guide was split into three main sections: the introduction (e.g. "Tell me how you started out as a swimming coach"), the formal portion (e.g. "Based on your coaching experience so far, what are your opinions of a quality based coaching philosophy?" and "Based on your coaching experience so far, what are your opinions on a quantity based coaching philosophy?") and conclusion ("Is there anything else you would like to add to the topics we discussed during the interview?"). Probes were used at various stages throughout the interview to increase the depth and complexity of participants' responses (Patton, 2015). Prior to the formal portion of the interview, a definition of a quality and quantity based coaching philosophy, as described by Maglischo (2003), was provided.

Following the semi-structured interview, each coach completed a closed-ended questionnaire that was designed to gather information about the coach's current training practices across all of the developmental stages of a competitive swimmer. The questionnaire was adapted from research by Krabak et al. (2013) and was pilot tested with two expert swimming coaches in order to establish validity. The Long Term Athlete Development (LTAD) model that is currently in use by the national governing body was suggested as the most practical method to categorise the distinct phases in the development of competitive swimmers within this cultural context (2014). The questionnaire was subsequently divided into 4 sections which were specific to the distinct phases within the LTAD model: Swim Skills Stage (Males 9-12 years and Females 8-11 years), Training to Train Stage (Males 12-15 years and Females 11-14 years), Training to Compete Stage (Males 15-18 years and Females 14-16 years) and Training to Win Stage (Males 18+ years and Females 16+ years). Each section contained 4 questions that were related to training frequency, training duration, training distance and energy systems.

\section{Procedures}

Approval to conduct this study was provided by the University of Limerick Ethics Committee. Prior to participating, all coaches were informed of the purpose of the study, provided written informed consent and were ensured of confidentiality. The coaches were classified as expert or top level in their country based on 3 criteria related to experience, achievement and qualification which had been used to define expert coaches in previous research (Thompson et al., 2009). The inclusion criteria for expert coaches were as follows: (a) they held a Level 3 swim coaching certification, the highest available coaching award from their national governing body; (b) they had a minimum of 10 years swim coaching experience; (c) they had coached at least 2 international level swimmers. A purposeful sample of expert coaches was recruited using a snowball sampling strategy in order to identify the most productive respondents to enhance the depth and richness of information gathered (Patton, 2015). The snowball sampling strategy was initiated by contacting two expert swimming coaches from different clubs. The coaches were informed of the inclusion criteria for the study and were asked to recommend any additional contacts who could provide different and/or confirming perspectives on the research 
topic. Subsequent interviews resulted in additional contacts, thus fulfilling the requirements of a snowball sampling strategy as defined by Patton (2015).

\section{Data Analysis}

Interviews were digitally recorded and transcribed verbatim by the first author. The interviews were imported into NVivo 10 (QSR International Pty, Ltd, 2012) for data analysis. A thematic analysis was conducted as outlined by Braun and Clarke (2006). The first phase involved familiarisation with the data in order to establish some initial ideas. The second phase involved generating codes which are defined as meaningful units of the text. The third phase involved sorting the codes into potential themes that reflected the overall content and meaning of the data. The final phase included further reviewing and defining of the themes. The questionnaire data was analysed using descriptive statistics (frequency of coach responses) and is summarised in Tables 1 and 2.

A number of procedures were employed to enhance the trustworthiness of the findings. Firstly, the interviews were conducted by the lead author who had previous swimming experience. This helped in establishing rapport and may have encouraged participants to provide more open and accurate answers. Secondly, data triangulation was achieved by using multiple sources (e.g. interview and questionnaire) which has been suggested to allow a better understanding of a phenomenon and strengthen the findings of a study (Creswell, 2013). In addition, participants were sent their interview transcript and were asked to confirm the accuracy of the information transcribed.

\section{Results}

The main themes that emerged from the interview findings were: (i) Quality programmes lead to short term results; (ii) Quality programmes are for senior swimmers; (iii) Building the aerobic base; (iv) The importance of slow swimming; (v) Break Point Volume. All of the themes are discussed and illustrated by representative quotes from the participants. Pseudonyms are used throughout to protect the identities of those provided in the text.

Theme 1: Quality programmes lead to short-term results

The majority of coaches consistently expressed concerns that quality programmes led to short-term results for youth swimmers. In many cases, they described quality programmes for youth swimmers as a "quick fix", "detrimental to long-term development" and "not sustainable". This coach stated: "There is a massive argument at the minute here in Ireland because you have swimmers who are doing a quality based programme, but they are getting results. Are those results going to be further down the road? I can't tell you and I'd say the coach doesn't know either." (Coach \#4). Concerns around the longterm development of youth swimmers who train using quality based programmes were further expressed by another coach:

"So if I look at a lot of successful youth swimmers that were from particular types of programmes, they usually weren't volume programmes, they were usually ones that were very intense and quality based. But they got to a particular point and they could never get past. That's where my philosophy got really based. What I feel is that you've got to take a step back and say, 'ok we could make them fast in a year or two but how is that going to effect them in 4 or 5 years time?'. I think that's the real developmental bit." (Coach \#9)

\section{Theme 2: Quality programmes are for senior swimmers}

Many of the coaches suggested that quality programmes were more appropriate for senior swimmers. The USA swim coach, "David Salo" was regularly quoted as one of the influencing factors behind this belief pattern. David Salo is one of the most widely known and successful proponents of a quality based training programme (Salo and Riewald, 2008). This coach highlighted the benefits of a quality training programme for distance swimmers:

"Over the years I've known coaches that have believed mileage, mileage, mileage makes swimmers better. I don't believe in that because mileage will make you fitter, but it won't make you faster. So what I mean for example is I've Jim (multiple senior distance record holder), he swims much better on a $55 \mathrm{~km}$ or below $55 \mathrm{~km}$ a week quality programme than he would when he was doing $70 \mathrm{~km}$ a week because he was always tired. He needs the race pace work to get better" (Coach \#3)

One coach appeared to have strong views on the benefits of a quality training programme for both sprint, middle distance and distance 
swimmers. This coach worked primarily with senior swimmers:

"We only train quality. There is this schism, there are people who believe it is volume, still believe it's volume. I don't. I don't believe it's volume anymore I believe it's speed. I don't believe swimming to be an endurance sport which most people will tell you it is. They will go, 'you need all the milleage'. Now I have to say here that we only have swimmers up to 200 metres at the moment so we race 50 to 200 metres. So it suits them to do nothing but speed so effectively we could be termed a sprint group, running a sprint program. If I had distance swimmers, I still probably wouldn't go down the serious volume route. I don't believe it. I don't believe it at all". (Coach \#5)

Following further probing into the reasoning behind these views, the coach stated:

"I think neuromuscular is the issue. The actual neural pathways that are fired. I think we are very obsessed by the physiology. Talk to a lot of coaches, 'oh yea he is doing twenty $100 \mathrm{~s}$ on 1.20 holding threshold etc etc etc.' Yea but he's now travelling at 1.09 for 2 hours. He has to race at 49 seconds, do you think the 2 hours neurologically, do you think that firing pattern is what he is going to use? They are different pathways, firing different pathways. So I think in that senses we have got lost and we've started doing too much volume." (Coach \#5)

\section{Theme 3: Building the aerobic base}

Nearly all of the coaches emphasised the importance of quantity training in building an aerobic base for youth swimmers. The process of building an aerobic base was described as "laying the foundations", "building the engine" and "building the pyramid layer by layer". The coaches consistently suggested that building an aerobic base was necessary in order to lay the foundations for success as an international swimmer. The coaches believed this was necessary for all types of youth swimmers regardless of their natural tendency towards sprint or distance events:

"My philosophy around that is simple and it's to do with developmental stages. If you want to build an engine you are building the heart, the lungs and the energy transport system. That's an endurance base. You want to build a system to be used later on whether you're a sprinter with fast twitch fibres or not. If you look at a lot of successful swimmers and forget the science behind it, where do they come from? They usually come from somewhere where they have done not a huge volume but a reasonable volume consistently at a young age but done very technically well. Then when they are older they have built that system, that's my philosophy. So they have built the base for a future date and they will be able to use that." (Coach \#9)

A number of the coaches consistently suggested that building an aerobic base in youth swimmers will help to enhance recovery from training and competition. The coaches felt this was a vital component that many people did not understand:

"People say 'well you guys train so much in swimming but you only race for a minute in a 100.' Yea but we don't just go and do one 100 you know if you're a breaststroker for example and you were at the European Championships last week, you would have raced over 7 days. If you were a good breaststroker you would have done the 50 - the heats and semi-final. You would have done the 100 - heats, semi-final. You would have done the 200 - heats, semi-final. And you might have been on the medley relay - heats and final. So you know that's 11 races over 7 days. If you haven't got some good aerobic background in you then you just won't make it." (Coach \#8)

One coach highlighted how they felt a quantity training programme during the developmental years of an Olympic sprint swimmer may have influenced the swimmers ability to recover from sprint training when she was a senior swimmer:

"If I took somebody like this girl that I used to coach - Janet who was a 100 and 200 freestyler in the Olympics. When she was an age group swimmer she was able to swim very, very efficiently at 200, 400, 800 and 1500 metres. As she got older she was definetely a sprinter. She could just stand up on the block and always be fast. So it was just a natural tendency for her to be fast. So what I felt was the work that we had done with her as an age grouper was always money in the bank for her. So we were able to put more focus on her speed work and so on as she became an older athlete. When she went on to college swimming the coach always commented that her fitness level was always so much better than anyone else and that allowed her to do more sprints and recover a lot quicker." (Coach \#11)

In contrast to this, there were a small number of coaches who expressed doubts around the common methods of building an aerobic base. One coach stated:

"There is that obsession that if you don't put in 
the so called aerobic base they will never be world class swimmers. Well I would question what is the aerobic base? How much of it do you need? And are there other ways of getting there? Besides just massive volume because that does work. If you throw enough at it, it will work. But what if there was other ways that get the children socially engaged in the sport and maybe it wasn't as brutal to them because it is. You know it's a hard sport to sell when you got to get up at 4 and $5 \mathrm{am}$ compared to say football or Gaelic football or rowing? I think you are destroying the children." (Coach \#5)

\section{Theme 4: The importance of slow swimming}

The majority of coaches believed that swimming slowly was vital to building good technique: "I think sometimes you've got to learn to swim slowly. You've got to learn to be able to swim technically well, slow, before you can swim it fast" (Coach \#4). Another coach suggested that swimming was not natural to humans and that swimming slowly for long periods of time would build better technique for faster swimming:

"I look at swimming as being one of the sports that is not natural to us. So one of the things that I've always felt about swimming was the fact that because it's so technique based you have to be in a place where you're relaxed and your technique becomes efficient so efficiency through good technique. And how do we get more efficient? By being able to apply that technique over longer periods of swimming and being able to swim at a slower pace and not always focus on swimming at a very fast pace. Because what happens is when you swim at a very fast pace the first thing that goes is your technique, your technique falls apart because you are unable to maintain that technique." (Coach \#11)

One coach suggested that the focus on slower swimming in quantity based training programmes provides better opportunities for technical development than a quality training programme due to the swimmer completing higher repetitions of a skill:

"We are a technique limited sport. You can only be as good as your skills are going to develop. If you look at it, my understanding from reading the current literature out there on skill acquisition is that you have to have a high level of repetitions of something before you turn a concise act into an unconcise habit. So there is great value from a technical point of view in having a programme that covers higher volumes at lower intensities because you have more opportunities to get a higher amount of correct repetitions." (Coach \#7)
However, a number of coaches suggested that it was still important for youth swimmers to practice swimming fast but this should be conducted using, "Short sprints for less than 10 seconds. There's no lactic acid building up and all that. HVO's...high velocity overloads, I believe in doing that with them." (Coach \#3)

\section{Theme 5: Break Point Volume}

Break Point Volume is a theory that was consistently mentioned throughout the interviews. Break Point Volume is a theory proposed by Bill Sweetenham, coach of multiple Olympic medallists in swimming and is defined as an optimal training volume performed at an optimal skill level that is achieved through a maximum number of training sessions at controlled intensities, which are predominantly aerobic, during maturation (Sweetenham, 2006). The theory outlines that swimming training programmes should build slowly and steadily towards a specific training volume that is achieved between 13 and 15 years of age (Sweetenham, 2006). The recommendations for achieving this specific training volume are 2000 to $2500 \mathrm{~km}$ of swimming spread over 42 to 46 weeks of the year and includes about 400 training sessions (Sweetenham, 2006).

Many of the coaches suggested that Break Point Volume theory was one of the main guiding principles within their coaching philosophy, however, many had trouble achieving the recommendations:

"So my programme has always been pitched around Bill Swettenham's Break Point Volume theories which are 2.2 million metres a year for developmental athletes for at least 4 to 5 years. So we tried to put that in place and I can show you where I think we delivered that over the course of a year which is an average of 45 to $50 \mathrm{~km}$ a week but the number of athletes who do it would always be quite small because things get in the way, life gets in the way." (Coach \#6)

A number of coaches suggested that the training recommendations within Break Point Volume theory should be conducted while taking the individual swimmer's lifestyle into account: "You've got to be careful with that term and we have kids coming through and some can't do as much as others and finding that is part of individual trainability. We're not forcing kids to do more than they can cope with." (Coach \#8).

A summary of the results from the closed- 
ended questionnaires are provided in Tables 1 and 2. All 11 coaches completed the questionnaire. The number of coach responses to each individual question is provided in the tables.
Table 1 displays the average swimming hours, average swimming training sessions and the average number of metres completed per week for each LTAD stage. Table 2 displays the energy systems order of importance for each LTAD stage.

Table 1

Average hours, sessions and metres of swimming per week for each LTAD stage (number of coach responses)

\begin{tabular}{|c|c|c|c|c|}
\hline Hours per week & $\begin{array}{l}\text { Swim } \\
\text { Skills* }\end{array}$ & $\begin{array}{c}\text { Training to } \\
\text { Train* }\end{array}$ & $\begin{array}{l}\text { Training to } \\
\text { Compete* }\end{array}$ & $\begin{array}{l}\text { Training to } \\
\text { Win* }\end{array}$ \\
\hline$<5$ hours & 3 & - & - & - \\
\hline 5 - 10 hours & 8 & 3 & - & - \\
\hline 11 - 15 hours & - & 8 & 6 & 2 \\
\hline 16 - 20 hours & - & - & 5 & 8 \\
\hline 21 - 25 hours & - & - & - & 1 \\
\hline$>25$ hours & - & - & - & - \\
\hline \multicolumn{5}{|l|}{ Sessions per week } \\
\hline$<3$ sessions & 2 & - & - & - \\
\hline $3-5$ sessions & 7 & 3 & - & - \\
\hline 6 - 8 sessions & 2 & 6 & 5 & - \\
\hline $9-11$ sessions & - & 2 & 5 & 10 \\
\hline 12 - 14 sessions & - & - & - & - \\
\hline >14 sessions & - & - & 1 & 1 \\
\hline \multicolumn{5}{|l|}{ Metres per week } \\
\hline$<5,000$ metres & 1 & - & - & - \\
\hline 5,001 - 10,000 metres & 3 & - & - & - \\
\hline 10,001 - 15,000 metres & 4 & - & - & - \\
\hline 15,001 - 20,000 metres & 3 & 3 & - & - \\
\hline 20,001 - 25,000 metres & - & 1 & 1 & - \\
\hline 25,001 - 30,000 metres & - & 1 & 2 & - \\
\hline 30,001 - 35,000 metres & - & 3 & 1 & 2 \\
\hline 35,001 - 40,000 metres & - & 3 & - & - \\
\hline 40,001 - 45,000 metres & - & - & 5 & 2 \\
\hline 45,001 - 50,000 metres & - & - & - & 1 \\
\hline 50,001 - 55,000 metres & - & - & - & 5 \\
\hline 55,001 - 60,000 metres & - & - & 1 & - \\
\hline 60,001 - 65,000 metres & - & - & - & - \\
\hline 65,001 - 70,000 metres & - & - & 1 & 1 \\
\hline$>70,000$ metres & - & - & - & - \\
\hline
\end{tabular}

*Swim Skills (M 9 - 12, F 8 - 11 yrs), Training to Train (M 12 - 15, F 11 - 14 yrs), Training to Compete (M 15 - 18, F $14-16$ yrs), Training to Win (M 18+, F 16+) 


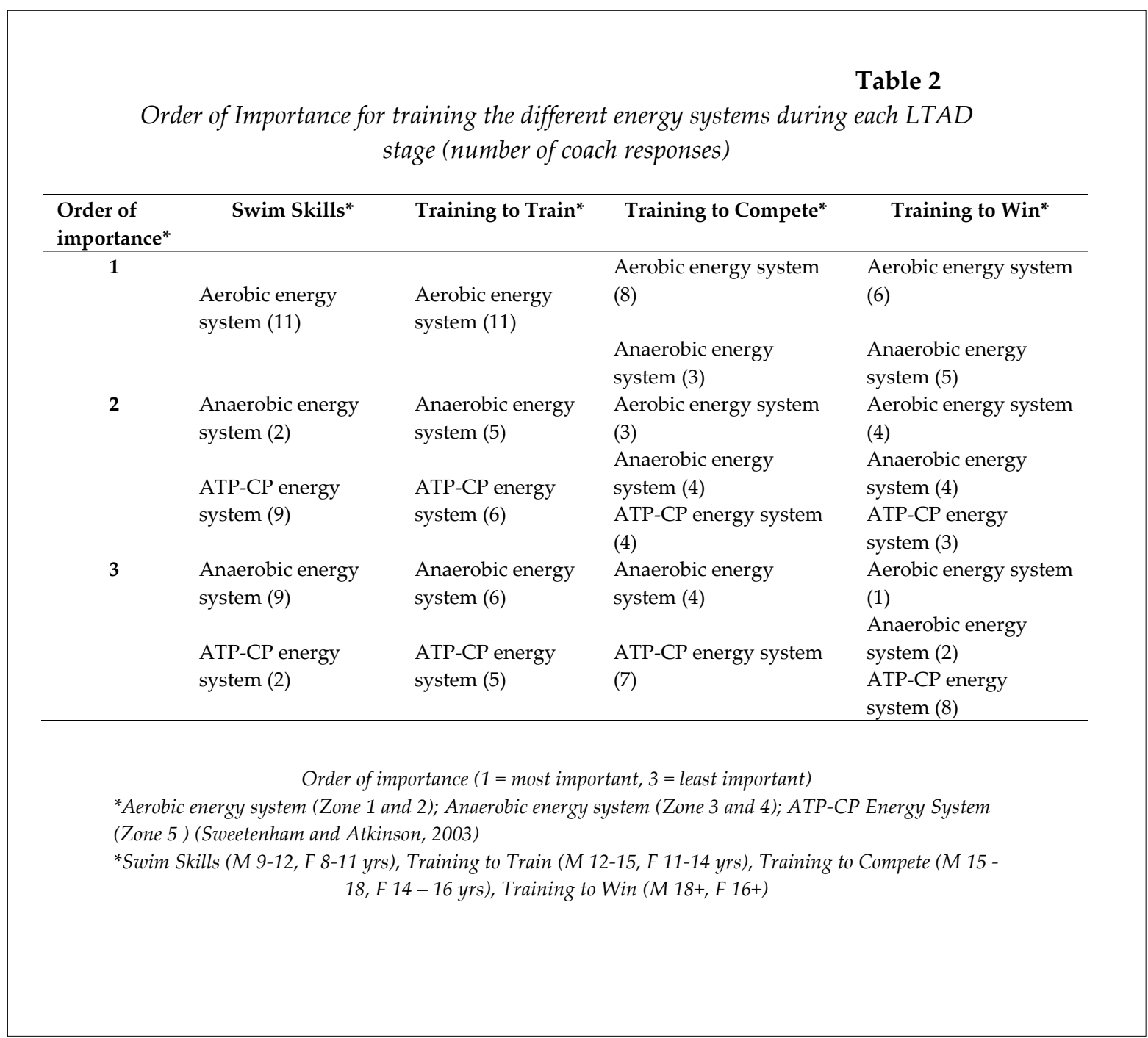

\section{Discussion}

The aim of this mixed methods study was to explore expert swimming coaches' perceptions of quality and quantity coaching philosophies and to investigate their current training practices. This study advances the current coaching and sports science literature by exploring the experiential knowledge of a cohort of expert Irish swimming coaches. This experiential knowledge is often based on day to day practice and performance experiences throughout a coaches' career (Greenwood et al., 2012). In this study, the expert swimming coaches' experiential knowledge helped to provide rich information on the quality vs quantity debate. The main themes that emerged from the interview findings were: (i) Quality programmes lead to short term results; (ii)
Quality programmes are for senior swimmers; (iii) Building the aerobic base; (iv) The importance of slow swimming; (v) Break Point Volume. The interview findings can be supported through data triangulation using the results of the questionnaire, thus fulfilling the requirements of a mixed methods study as outlined by Creswell (2013). In addition, further data triangulation of the interview findings was conducted using the current literature.

\section{Theme 1: Quality programmes lead to short-term results}

The interview findings indicated the wide held perception that quality programmes may lead to short-term results in youth swimmers. The coaches suggested that a quantity coaching philosophy focused on higher volume swimming at lower aerobic intensities was needed. This 
finding appears to be evident in Table 2 where $100 \%$ of the coaches surveyed $(n=11)$ indicated that the aerobic energy system or training zone 1 and 2 in Sweetenham and Atkinson (2003) was the most important energy system to develop during the Swim Skills (Males 9-12 years and Females 811 years) and Training to the Train stage (Males 12-15 years and Females 11-14 years) of development.

A small number of coaches interviewed indicated that short sprints of less than 10 seconds were important for youth swimmers and called these "high velocity overloads" or HVO's. The importance of these short sprints appears to be evident in Table 2 where 9 out of 11 (81.8\%) coaches indicated that the ATP-CP energy system or training zone 5 in Sweetenham and Atkinson (2003) was the second most important energy system to develop during the Swim Skills stage (Males 9-12 years and Females 8-11 years) of development.

A recent systematic review by Nugent et al. (2016) found only 2 studies involving quality or HIT interventions in youth swimmers. The studies involved a $40-50 \%$ reduction in training volume for duration of $4-5$ weeks and resulted in significant improvements in physiological performance $\left(\mathrm{V}_{2}{ }_{\max }\right.$, sub-maximal lactate indices and peak lactate indices) as well as swimming performance (Faude et al., 2008; Sperlich et al., 2010). However the $4-5$ week duration of both studies is short and therefore, the long term applications of this type of training intervention remain unknown.

An expert commentary article by Greyson et al. (2010) advises against too much anaerobic training at a young age as it will result in the reduction in swimmer's potential to be a successful international swimmer. Greyson et al. (2010) also suggest that swimming technique is best developed during aerobic swimming as technique is difficult to maintain during anaerobic swimming.

\section{Theme 2: Quality programmes are for senior swimmers}

The interview findings indicated that quality programmes may be more appropriate for senior swimmers. In support of this, many of the coaches suggested that their philosophies were influenced by the theory of Break Point Volume which suggests that youth swimmers should focus on quantity training during maturation with quality training, that is more anaerobic in nature, becoming more prominent as a swimmer reaches full maturation (Sweetenham, 2006). Table 2 displays a trend towards Break Point Volume theory as highlighted by an evident shift towards developing the anaerobic energy system or training zone 3 and 4 in Sweetenham and Atkinson (2003) during the Training to Win stage (Males 18+ years and Females $16+$ years) with 5 out of 11 coaches $(45.4 \%)$ indicating that the anaerobic energy system was the most important energy system to develop at this stage.

The systematic review by Nugent et al. (2016) identified 4 HIT studies that were conducted on senior swimmers (Houston et al., 1981; Kame et al., 1990; Kilen et al., 2014; Termin and Pendergast, 2000). The studies ranged in duration from 6.5 weeks to 4 years. Three of the studies resulted in significant increases in physiological performance (V02max, V02peak and peak lactate indices) and swimming performance. None of the 4 studies resulted in a reduction in physiological or swimming performance following a HIT intervention. Despite these positive findings, the exercise testing modalities (Houston et al., 1981), short duration (Houston et al., 1981), and lack of an appropriate control group (Kame et al., 1990; Termin and Pendergast, 2000) in many of the studies are a concern.

\section{Theme 3: Building the aerobic base}

The interview findings indicated that building the aerobic base was vital for youth swimmers. These findings are evident across Tables 1 and 2. Table 1 highlights the average training hours, number of sessions and number of metres completed per week. Table 1 displays a clear and linear increase in training hours, the number of sessions and number of metres completed per week from the Swim Skills (Males 9-12 years and Females 8-11 years) to the Training to Win stage (Males 18+ years and Females $16+$ years) of development. For example, four out of 11 coaches (36.4\%) indicated that $10-15,000$ metres per week was their average training distance prescribed during the Swim Skills stage (Males 9-12 years and Females 8-11 years), while five out of 11 coaches $(45.4 \%)$ indicated that $50-$ 50,000 metres per week was their average training distance prescribed during the Training to Win stage (Males 18+ years and Females $16+$ years) of 
development.

Table 2 provides further support to the theme of "building the aerobic base" as $100 \%$ of the coaches surveyed $(n=11)$ indicated that the aerobic energy system or training zone 1 and 2 in Sweetenham and Atkinson (2003) was the most important energy system to develop during the Swim Skills (Males 9-12 years and Females 8-11 years) and Training to Train stage (Males 12-15 years and Females 11-14 years) of development.

Nearly all of the coaches in our study continuously emphasised the importance of building the aerobic base with good technique as many of the coaches felt that people misunderstood this aspect and that in many cases quantity programmes, which build an aerobic base, could lead to poor technique. This is a similar theme to that previously reported by Lang and Light (2010) who explored English swimming coach's views on the LTAD model outlined by the Amateur Swimming Association. The main findings of the Lang and Light (2010) study were that the coaches felt there was an overemphasis on training volume in the LTAD model at the expense of technique.

\section{Theme 4: The importance of slow swimming}

The interview findings indicated that slow swimming was vital to building good technique. This finding appears to be evident in Table 2 as $100 \%$ of the coaches surveyed $(n=11)$ indicated that the aerobic energy system or training zone 1 and 2 in Sweetenham and Atkinson (2003) was the most important energy system to develop during the Swim Skills (Males 9-12 years and Females 8-11 years) and Training to Train stage (Males 12-15 years and Females 1114 years) of development.

In addition, an expert commentary article by Greyson et al. (2010) suggests that swimming technique is best developed at slower speeds, thus pointing towards the use of aerobic swimming in order to develop good technique.

\section{Theme 5: Break Point Volume}

The interview findings indicated that Break Point Volume theory was one of the main guiding principles for many of the coaches' philosophies. These findings are evident across Tables 1 and 2. Table 1 highlights the average training hours, number of sessions and number of metres completed per week. The recommendations within Break Point Volume theory of roughly building towards 45 to 55,000 metres per week during maturation appear to be evident within Table 1 . Five out of 11 coaches (45.4\%) indicated that $40-45,000$ metres per week was their average training distance prescribed during the Training to Compete stage (Males 1518 years and Females 14-16 years). However, for all 11 coaches this prescription ranged from 2025,000 metres to $65-70,000$ metres per week. In addition, five out of 11 coaches (45.4\%) indicated that 50-55,000 metres per week was the average training distance prescribed during the Training to Win stage (Males 18+ years and Females $16+$ years) of development. Similarly, for all 11 coaches this prescription ranged from $30-35,000$ metres to 65-70,000 metres per week.

Break Point Volume theory suggests that youth swimmers should focus on quantity training during maturation with quality training, that is more anaerobic in nature, becoming more prominent as a swimmer reaches full maturation (Sweetenham, 2006). Table 2 displays a similar trend towards Break Point Volume theory as highlighted by an evident shift towards developing the anaerobic energy system or training zone 3 and 4 in Sweetenham and Atkinson (2003) during the Training to Win stage (Males 18+ years and Females $16+$ years) with 5 out of 11 coaches $(45.4 \%)$ indicating that the anaerobic energy system was the most important energy system to develop at this stage.

There are a number of limitations to the present study. The sample only consisted of Irish swimming coaches and potentially the culture of the sport within the country may have systematically influenced the results. Therefore, the results are valid within the cultural context and overall training philosophy of that particular country. The results of the questionnaire were limited due to the obvious overlap between the LTAD stages and the low number of participants. The questionnaire was pilot tested and the LTAD model was agreed by the coaches as the best available description of the various developmental stages within a club structure for competitive swimmers in that particular country. Nevertheless, overlap clearly exists between groups.

Emerging trends within the swimming community and scientific literature have resulted in many questions around quality and quantity 
coaching philosophies. The authors felt that the coaches' high level experiential knowledge within the sport would help to provide a context and valuable information on this topic from an applied perspective. To the best of the authors' knowledge, this was the first study to explore expert swimming coaches' perceptions of the Quality vs Quantity debate. The explorative nature of this study provides additional incentive to conduct further quantitative research involving HIT interventions in competitive swimmers. Controlled studies of longer duration are needed ( $\geq 12$ weeks) using outcome measures of physiological, biomechanical and swimming performance.

\section{Acknowledgements}

The authors would like to thank the swimming coaches who kindly volunteered their time to partake in the study. This study was part-funded by the National Aquatic Centre Swimming Club, Dublin, Ireland.

\section{References}

A Pathway to Aquatic Development in Ireland. Ireland: Swim Ireland; 2014

Aspenes S, Karlsen T. Exercise-training intervention studies in competitive swimming. Sports Med, 2012; 42: 527-543

Balyi I, Hamilton A. Long-Term Athlete Development - Trainability in Childhood and Adolescence, Windows of Opportunity and Optimal Trainability. Victoria: National Coaching Institute British Columbia \& Advanced Training and Performance Ltd; 2004

Beliaev S. Ultra-Short Race-Pace Training - breakthrough or a phantom from the past? Swimming Technique. USA: Swimming World Magazine, 2015; 5-7

Braun V, Clarke V. Using thematic analysis in psychology. Qualitative Research in Psychology, 2006; 3: 77-101

Costill DL, Thomas R, Robergs RA, Pascoe D, Lambert C, Barr S, Fink WJ. Adaptations to swimming training: influence of training volume. Med Sci Sports Exerc, 1991; 23: 371-377

Creswell JW. Qualitative Inquiry and Research Design. Choosing Among Five Approaches. 3rd ed. USA: Sage; 2013

Faude O, Meyer T, Scharhag J, Weins F, Urhausen A, Kindermann W. Volume vs. intensity in the training of competitive swimmers. Int J Sports Med, 2008; 29: 906-912

Goldsmith W. The Distance Debate: How much swim training should we be doing? Swimming World. USA: Sports Publications Inc; 2016

Greenwood D, Davids K, Renshaw I. How Elite Coaches' Experiential Knowledge Might Enhance Empirical Research on Sports Performance. Int J Sports Sci Coach, 2012; 7: 411 - 422

Greyson I, Kelly S, Peyrebrune M, Furniss B. Interpreting and Implementing the Long Term Athlete Development Model: English Swimming Coaches' Views on the (Swimming) LTAD in Practice. A Commentary. Int J Sports Sci Coach, 2010; 5: 403-406

Hawley JA, Myburgh KH, Noakes TD, Dennis SC. Training techniques to improve fatigue resistance and enhance endurance performance. J Sports Sci, 1997; 15: 325-333

Hibberd EE, Myers JB. Practice habits and attitudes and behaviours concerning shoulder pain in high school competitive club swimmers. Clin J Sport Med, 2013; 23(6): 450-5

Houston ME, Wilson DM, Green HJ, Thomson JA, Ranney DA. Physiological and muscle enzyme adaptations to two different intensities of swim training. Eur J Appl Physiol Occup Physiol, 1981; 46: 283291

Kame VD, Pendergast DR, Termin B. Physiologic Responses to High Intensity Training in Competitive University Swimmers. J Swim Res, 1990; 6: 5-8

Kilen A, Larsson TH, Jørgensen M, Johansen L, Jørgensen S, Nordsborg NB. Effects of 12 weeks highintensity \& reduced-volume training in elite athletes. PLoS One, 2014; 9(4): 1-8 
Krabak BJ, Hancock KJ, Drake S. Comparison of Dry-Land Training Programs Between Age Groups of Swimmers. PmER, 2013; 5: 303-309

Lang M, Light R. Interpreting and Implementing the Long Term Athlete Development Model: English Swimming Coaches' Views on the (Swimming) LTAD in Practice. Int J Sports Sci Coach, 2010; 5: 407412

Lloyd RS, Oliver JL. The Youth Physical Development Model: A New Approach to Long-Term Athletic Development. Strength and Conditioning Journal, 2012; 34: 61-72

Maglischo EW. Quality Versus Quantity. Swimming Fastest. USA: Human Kinetics, 414-415; 2003

Mayan M. Essentials of qualitative inquiry. USA: Left Coast Press, Inc.; 2009

Morais J, Silva A, Marinho D, Lopes V, Barbosa T. Determinant Factors of Long-Term Performance Development in Young Swimmers. Int J Sports Physiol Perform, 2016; doi: 10.1123/IJSPP.2015-0420. Epub ahead of print

Morais JE, Silva AJ, Marinho DA, Seifert L, Barbosa TM. Cluster stability as a new method to assess changes in performance and its determinant factors over a season in young swimmers. Int J Sports Physiol Perform, 2015; 10: 261-268

Nugent FJ, Comyns TM, Burrows E, Warrington GD. Effects of Low Volume, High-Intensity Training on Performance in Competitive Swimmers: A Systematic Review. J Strength Cond Res, 2017; 31(3): 837-847; doi: 10.1519/JSC.0000000000001583

Patton MQ. Qualitative Research \& Evaluation Methods: Integrating Theory and Practice. 4th ed. USA: SAGE Publications Inc.; 2015

Pyne DB, Lee H, Swanwick KM. Monitoring the lactate threshold in world-ranked swimmers. Med Sci Sports Exerc, 2001: 291-297

Rushall BS. Swimming energy training in the 21st century: the justification for radical changes. 2nd ed. Coachsci.sdsu.edu: Swimming Science Bulletin; 2011

Salo D, Riewald SA. Swimming-Specific Training. In: Complete Conditioning for Swimming. USA: Human Kinetics, 37; 2008

Sperlich B, Zinner C, Heilemann I, Kjendlie PL, Holmberg HC, Mester J. High-intensity interval training improves VO2peak, maximal lactate accumulation, time trial and competition performance in 9-11year-old swimmers. Eur J Appl Physiol, 2010; 110: 1029-1036

Stott MJ. A new way to train. Swimming World. USA: Sports Publications Inc, 25-29; 2014

Sweetenham B. Break Point Volume. American Swimming Magazine. USA: American Swimming Coaches Association, 2006; 34-36

Sweetenham B, Atkinson J. Training Systems. In: Championship Swim Training. USA: Human Kinetics, 3-16; 2003

Termin B, Pendergast DR. Training using the Stroke Frequency - Velocity Relationship to combine Biomechanical \& Metabolic Paradigms. J Swim Res, 2000; 14: 9-17

Thompson A, Bezodis IN, Jones RL. An in-depth assessment of expert sprint coaches' technical knowledge. J Sports Sci, 2009; 27: 855-861

\section{Corresponding author:}

\section{Frank Nugent}

Department of Physical Education and Sport Sciences

University of Limerick, Limerick, Ireland

Phone: +353851506074.

E-mail: frank.nugent@ul.ie 